\title{
Comparison of different vegetation indices for very high-resolution images, specific case UltraCam-D imagery
}

\author{
Maryam Barzegar*a, Hamid Ebadi ${ }^{\text {b }}$, Abbas Kianic \\ a* Corresponding author, BSc student, K. N. Toosi University of Technology, Tehran, Iran - maryambarzegar119@ yahoo.com; \\ ${ }^{\mathrm{b}}$ Associate professor of Geodesy and Geomatics Eng. faculty, K. N. Toosi University of Technology, Tehran, Iran- \\ ebadi@kntu.ac.ir; \\ ${ }^{\mathrm{c}}$ PhD Candidate Geodesy and Geomatics Eng. faculty, K.N.Toosi University of Technology,Tehran, Iran- \\ Abbasekiani@yahoo.com;
}

KEY WORDS: Vegetation indices, High-resolution images, UltraCam, DVI

\begin{abstract}
Today digital aerial images acquired with UltraCam sensor are known to be a valuable resource for producing high resolution information of land covers. In this research, different methods for extracting vegetation from semi-urban and agricultural regions were studied and their results were compared in terms of overall accuracy and Kappa statistic. To do this, several vegetation indices were first tested on three image datasets with different object-based classifications in terms of presence or absence of sample data, defining other features and also more classes. The effects of all these cases were evaluated on final results. After it, pixel-based classification was performed on each dataset and their accuracies were compared to optimum object-based classification. The importance of this research is to test different indices in several cases (about 75 cases) and to find the quantitative and qualitative effects of increasing or decreasing auxiliary data. This way, researchers who intent to work with such high resolution data are given an insight on the whole procedure of detecting vegetation species as one of the outstanding and common features from such images. Results showed that DVI index can better detect vegetation regions in test images. Also, the object-based classification with average 93.6\% overall accuracy and $86.5 \%$ Kappa was more suitable for extracting vegetation rather than the pixel-based classification with average $81.2 \%$ overall accuracy and $59.7 \%$ Kappa.
\end{abstract}

\section{INTRODUCTION}

Vegetation is counted as one of the most important components of each ecosystem. Determining vegetation regions is crucial to understand the interactions between earth and atmosphere, its effects on climate, soil erosion and drought, and for natural resource management. Now, photogrammetry and remote sensing are one of the most important technologies to acquire and/or produce such information. Nowadays, digital aerial images taken with advanced UltraCam sensor are used extensively in our country and are known to be a valuable resource to produce high resolution land cover information.

Image processing techniques are categorized in two broad classes. The first ones, are those in which their processing unit is a single pixel. These techniques are called pixel-based and are highly used for extracting descriptive information. In cases where the region under study has the same size with image pixel, pixel-based methods can achieve acceptable results (Blaschke, 2010). Therefore, these methods can perform properly on low or mid resolution images (Wei, 2009). In recent years, with the advent of high resolution images, limitations of pixel-based methods are gradually revealed. Despite spectral features, additional information such as texture, geometry and shape indices can be extracted from high resolution images with low and mid-level processes. Because of low variation in spectral information of high resolution images, using only spectral features can make some problems in high level processes. As an example, for urban applications of such images, objects like buildings and roads might contain a number of pixels. So, using a single pixel instead of a group of pixels may lead to errors in final results. Some researchers have reported the pepper-salt noise in results of implementing pixel-based methods on high resolution images (Liu, 2008; $\mathrm{Pu}, 2011$ ). Also, results of such methods are not matched well with reality.

The second class of image processing techniques are objectbased. The application of such methods holds back to 70s (Yan, 2006). Here, processing unit is a homogenous group of pixels (as image object) and the image is processed in object space instead of pixel space. In such methods, the image is first segmented and then classified. Each segment is known as a meaningful object. These methods have some advantages over pixel-based methods including: 1- Because of using objects instead of single pixels, all aspects of remote sensing field such as spectral and spatial information, morphological and structural information, context information and also temporal information can be involved. 2- These methods can use geospatial information systems as an auxiliary data, distance criteria etc. 3- Objects can be formed in different sizes and in multi-scale levels of the image. So, one can first remove the unwanted additional objects in a bigger scale and then focus on extracting desirable objects. Moreover, to create image objects in different levels, parent-child relationships can be used to improve the process of detecting and extracting objects for change detection applications (Navulur, 2006).

There are many researches in literature for extracting vegetation in urban areas. Li and Shao (2014) produced land 
cover maps of west America using object-oriented classification and multi-scale segmentation of high resolution aerial images. They used NDVI to extract vegetation. Several other studies have been dedicated to compare different vegetation indices. Barati et al. (2011) evaluated different vegetation indices on IRS-LISIII image and found that DVI was the best index for the region. Also, many researches have compared pixel-based and objectoriented classifications. Myint et al. (2011) extracted vegetation from Quickbird image using both classifiers. Results showed that object-oriented classification could achieve $93.03 \%$ overall accuracy and $91.81 \%$ Kappa while pixel-based classifier got $80 \%$ and $76.31 \%$ respectively. They reported the lowest accuracy of extracting vegetation and soil classes due to their mix with other classes.

In this research, after studying recent methods with their results and their pros and cones, several cases (about 75 ones) were designed to compare quantitative and qualitative effects of increasing or decreasing auxiliary data. These cases evaluate the presence or absence of sample data, different vegetation indices (10 indices), using other features (redness, coloration, hue, saturation, brightness and NDWI), defining other classes (soil, artificial objects, shadow etc.), imaging conditions, whether to use near infrared bands or not (i.e. only RGB bands), all to find the optimum object-based classification and vegetation index for Ultracam images. Also, object-based and pixel-based classifications were compared to each other.

\section{MATERIALS AND METHODS}

\subsection{Data}

Test images used in this study cover two different climates. The first study region is a part of Alborz area in Mazandaran, Bandar-Anzali and the second region is in Tehran, Damavand and near Absard region.

Both datasets are images form UltraCam D with $8 \mathrm{~cm}$ ground pixel size. One image from the first region (image 1) and two images from the second region acquired in two flight lines (images $2 \& 3$ ) are used to study different imaging situations. Ground truth map was provided visually based on archived information.

\subsection{Segmentation}

Segmentation refers to dividing image into uniform nonoverlapped conceptual regions which are named image objects or image segments. In other words, a group of neighborhood pixels with a similar property such as gray level, texture, shape and scale is called an image object.

In this research, multi-resolution segmentation is used. This method can use texture, shape, size, spectral and spatial characteristics, and previous information. It is able to extract objects with different sizes and weighting parameters like color, size, shape etc. In this segmentation, image objects are given weights according to their pixel size and the average heterogeneity of two adjacent objects is quantified based on "degree of fitting" criteria (Eq. 1).

$$
h_{\text {diff }}=\sum_{c} w_{c}\left(n_{1}\left(h_{m c}-h_{1 c}\right)+n_{2}\left(h_{m c}-h_{2 c}\right)\right)
$$

$$
\begin{aligned}
& \mathrm{c}=\text { number of channels } \\
& n_{1} \& n_{2}=\text { size of adjacent objects } \\
& w_{c}=\text { weight of each channel }
\end{aligned}
$$

If the "degree of fitting" for adjacent objects is lower than the defined "least degree of fitting" the objects are merged together (Baatz and Schape, 2000).

\subsection{Classification}

To perform the object-oriented classification, nearest neighbor method is used. In this approach, a group of n-pairs $\left\{\left(\mathrm{x}_{1}, \Theta_{1}\right), \ldots,\left(\mathrm{x}_{\mathrm{n}}, \Theta_{\mathrm{n}}\right)\right\}$ is defined where $\mathrm{X}$ stands for image object and $\Theta$ stands for class. The nearest neighborhood rule studies the following equation (Eq. 2):

$$
\begin{gathered}
\min d\left(x_{1}, x\right)=d\left(x^{\prime}{ }_{n}, x\right) \\
\text { Where } \quad \begin{array}{l}
x_{n}^{\prime} \in\left\{x_{1}, x_{2}, \ldots, x_{n}\right\}, \\
i=1,2, \ldots, n .
\end{array}
\end{gathered}
$$

If the above equation is satisfied, then $\mathrm{x}$ is related to class $\Theta_{\mathrm{n}}^{\prime}$ which contains X'n objects (Cover and Hart, 1967).

\section{THE PROPOSED METHOD}

Different methods for vegetation extraction (pixel-based and object-based) where studied in semi-urban and agricultural regions. Fig. 1 describes the flowchart of object-based classification.

To find the optimum vegetation index, 10 different vegetation indices (Table 1) were studied according to the flowchart illustrated at Fig. 1. Then using this index (DVI) other cases of object-oriented classification were evaluated. These cases include the following 4 ones:

1. Defining vegetation class + vegetation index

2. Defining vegetation class + vegetation index + other classes (water, soil etc.)

3. Defining vegetation class + vegetation index + other classes (water, soil etc.) + other features (Table 2)

4. Defining vegetation class + vegetation index + other classes (water, soil etc.) + other features + sampling

In this investigation, only BI and NDWI features improved the classification result and because they had same results, NDWI feature was used to study other cases. All objectbased classifications were performed by eCognition 8.7.2. After this, pixel-based classification was carried out for the three test images and the results were compared to optimum object-based classification in terms of overall accuracy and Kappa. The next section discusses these results.

\section{RESULTS AND SUGGESTIONS}

In this research, 10 different vegetation indices were studied using one cases of object-based classifications to find the optimum index (Table 3). In addition, three other classification cases were evaluated (Table 4). After it, pixelbased classification was carried out for the three test images 
and its results were compared to optimum object-based classification (Table 5).
Fig. 2 illustrates result of optimum $\mathrm{OBC}$, ground truth image and pixel based classification for image 1, fig. 3 for image 2 and fig. 4 for image 3.

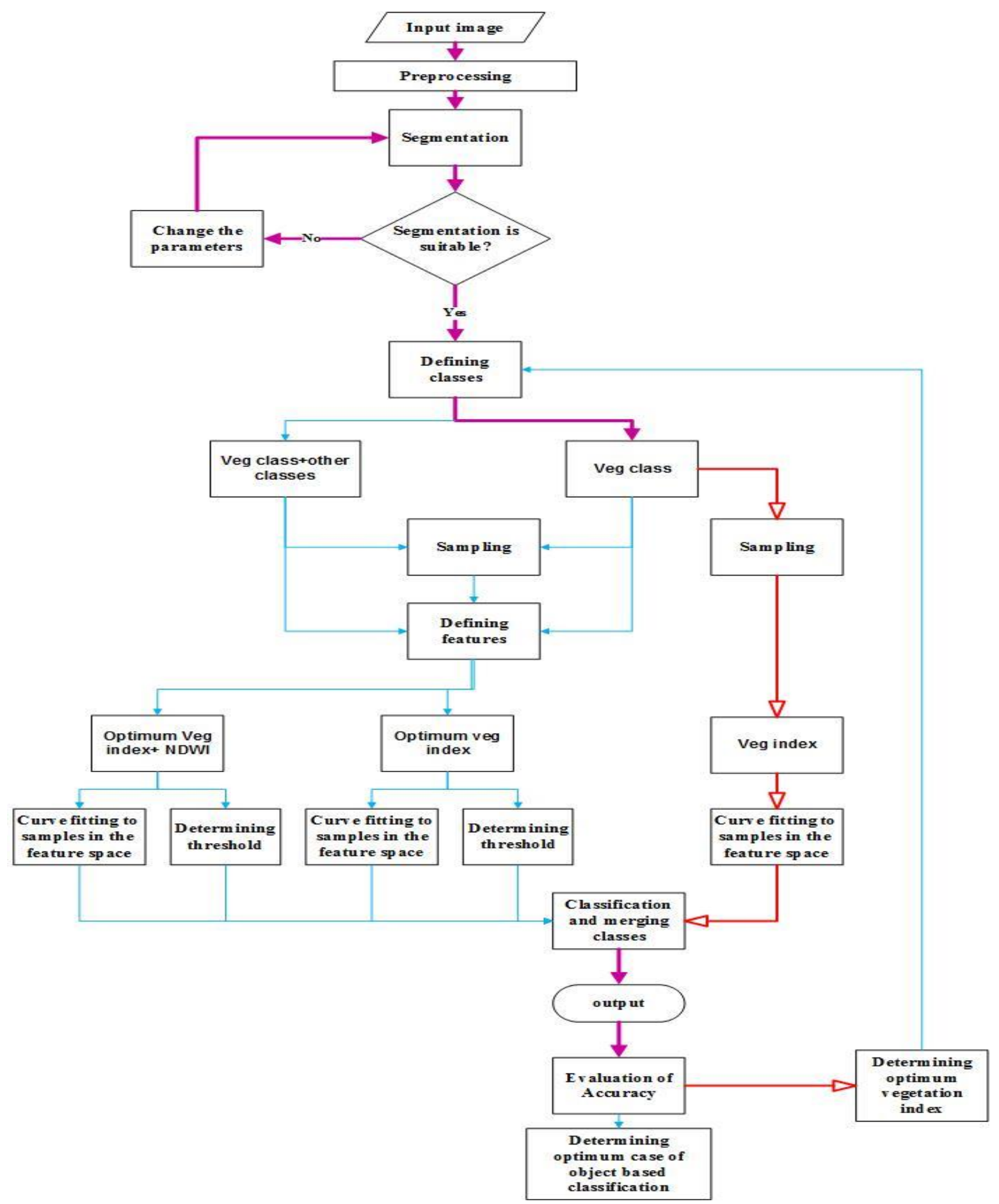

Fig 1. General process of object-based classification $(\stackrel{\rightarrow}{ }$ : The process of finding optimum vegetation index, $\rightarrow$ : The process was done for different cases of object-based classification after finding optimum vegetation index, $\rightarrow$ :common procedures in both of the processes.) 
The International Archives of the Photogrammetry, Remote Sensing and Spatial Information Sciences, Volume XL-1/W5, 2015

\begin{tabular}{|c|c|c|}
\hline Inflaterr & ional ConfEremedaon Sensor & \& ModeRsfiprdRenqote Sen \\
\hline NDVI & $\frac{\rho_{N I R}-\rho_{R}}{\rho_{N I R}+\rho_{R}}$ & (Rouse, 1973) \\
\hline DVI & $\rho_{N I R}-\rho_{R}$ & (Tucker, 1980) \\
\hline SAVI & $\begin{array}{c}(1+\mathrm{L}) *[(\mathrm{NIR}-\mathrm{red}) /(\mathrm{NIR}+ \\
\text { red }+\mathrm{L})] \\
\text { Where } \mathrm{L}=0.5\end{array}$ & (Huete, 1988) \\
\hline GARI & $\begin{array}{c}\text { NIR - [green - (blue }- \text { red })] / \\
\text { NIR [green - (blue }- \text { red })]\end{array}$ & (Gitelson et al, 1996) \\
\hline GNDVI & $\begin{array}{c}(\mathrm{NIR}-\text { green }) /(\mathrm{NIR}+ \\
\text { green })\end{array}$ & $\begin{array}{c}\text { (Buschmann and Nagel, } \\
1993 \text { ) }\end{array}$ \\
\hline $\mathrm{Cl}$ & $(\mathrm{NIR} / \mathrm{G})-1$ & $\begin{array}{l}\text { (Vescovo and Gianelle, } \\
\text { 2008) }\end{array}$ \\
\hline RDVI & $\begin{array}{l}(N D V I * D V I)^{\frac{1}{2}} \\
=\frac{N I R-R}{\sqrt{N I R+R}}\end{array}$ & $\begin{array}{c}\text { (Roujean and Breon, } \\
1995)\end{array}$ \\
\hline EGI & $3 *\left(\frac{G}{R+G+B}\right)-1$ & (Wobbecke et al, 1995) \\
\hline DGR & $\frac{G-R}{R+G+B}$ & (Wobbecke et al, 1995) \\
\hline NDI & $\frac{G-R}{G+R}$ & (Bargen et al, 1995) \\
\hline
\end{tabular}

\begin{tabular}{|c|c|c|}
\hline $\begin{array}{c}\text { רotogramme } \\
\text { lndex }\end{array}$ & $\begin{array}{c}\text { y, 23-25 Nov 2015, Kish } \\
\text { Formula }\end{array}$ & $\begin{array}{l}\text { land, Iran } \\
\text { References }\end{array}$ \\
\hline $\begin{array}{l}\text { Brightness } \\
\text { Index, BI }\end{array}$ & $\left(\left(R^{2}+G^{2}+B^{2}\right) / 3\right)^{0.5}$ & $\begin{array}{c}\text { (Mathieu et } \\
\text { al, 1998) }\end{array}$ \\
\hline $\begin{array}{c}\text { Saturation } \\
\text { Index, SI }\end{array}$ & $(R-B) /(R+B)$ & $\begin{array}{c}\text { (Mathieu et } \\
\text { al, 1998) }\end{array}$ \\
\hline $\begin{array}{c}\text { Hue Index, } \\
\text { HI }\end{array}$ & $(2 * R-G-B) /(G-B)$ & $\begin{array}{c}\text { (Mathieu et } \\
\text { al, 1998) }\end{array}$ \\
\hline $\begin{array}{c}\text { Coloration } \\
\text { Index, CI }\end{array}$ & $(R-G) /(R+G)$ & $\begin{array}{c}\text { (Mathieu et } \\
\text { al, 1998) }\end{array}$ \\
\hline $\begin{array}{l}\text { Redness } \\
\text { Index, RI }\end{array}$ & $R^{2} /\left(B * G^{3}\right)$ & $\begin{array}{c}\text { (Mathieu et } \\
\text { al, 1998) }\end{array}$ \\
\hline NDWI & $(G-N I R) /(G+N I R)$ & $(\mathrm{Gao}, 1996)$ \\
\hline
\end{tabular}

Table 2. features used in classification

Table 1. Vegetation indexes investigated in test images

\begin{tabular}{|c|c|c|c|c|c|c|c|c|c|c|c|}
\hline \multicolumn{2}{|c|}{ Index } & EGI & DGR & NDI & DVI & $\mathrm{cl}$ & NDVI & RDVI & GARI & GNDVI & SAVI \\
\hline \multirow{2}{*}{ Image 1 } & $\begin{array}{c}\text { Overall } \\
\text { accuracy(\%) }\end{array}$ & 69.7244 & 65.7028 & 65.8669 & 91.1715 & 73.5382 & 79.9260 & 82.8809 & 70.9069 & 83.2452 & 80.0219 \\
\cline { 2 - 11 } & Kappa(\%) & 16.6413 & 1.2008 & 1.7613 & 80.0359 & 30.2592 & 50 & 57.1617 & 19.7987 & 59.5216 & 48.8896 \\
\hline \multirow{2}{*}{ Image 2 } & $\begin{array}{c}\text { Overall } \\
\text { accuracy(\%) }\end{array}$ & 50.3200 & 49.9574 & 50.2118 & 98.4168 & 87.8429 & 93.2461 & 96.6923 & 88.0490 & 79.0827 & 92.8410 \\
\cline { 2 - 12 } & Kappa(\%) & 1.8771 & 1.1639 & 1.6467 & 96.8318 & 75.7426 & 86.5063 & 93.3797 & 76.1493 & 58.3703 & 85.6887 \\
\hline \multirow{2}{*}{ Image 3 } & $\begin{array}{c}\text { Overall } \\
\text { accuracy(\%) }\end{array}$ & 41.8607 & 45.9290 & 52.6118 & 88.2388 & 57.1921 & 72.8516 & 95.8819 & 86.7387 & 60.5503 & 80.3779 \\
\cline { 2 - 12 } & Kappa(\%) & 2.0993 & 7.6846 & 16.3555 & 74.5165 & 23.9870 & 48.9497 & 91.3708 & 73.6981 & 29.1314 & 62.0253 \\
\hline
\end{tabular}

Table 3. Results of different cases of object oriented classification for test images

\begin{tabular}{|c|c|c|c|c|c|c|}
\hline \multicolumn{2}{|c|}{ Case of OBC } & $\begin{array}{c}\text { Veg class+ } \\
\text { other classes+ } \\
\text { DVI }\end{array}$ & Veg class+ DVI & $\begin{array}{c}\text { Veg class+ other } \\
\text { classes+ NDWI+ DVI }\end{array}$ & $\begin{array}{c}\text { Veg class+ other classes+ } \\
\text { sample+ NDW+ DVI }\end{array}$ & $\begin{array}{c}\text { Veg class+ DVI+s } \\
\text { ample }\end{array}$ \\
\hline \multirow{3}{*}{ Image 1 } & $\begin{array}{c}\text { Overall } \\
\text { accuracy(\%) }\end{array}$ & 88.7000 & 88.7014 & 88.7015 & 90.7446 & 91.1715 \\
\cline { 2 - 7 } & Kappa(\%) & 75.8540 & 75.8537 & 75.8541 & 79.3954 & 80.0395 \\
\hline \multirow{3}{*}{ Image 2 } & $\begin{array}{c}\text { Overall } \\
\text { accuracy(\%) }\end{array}$ & 94.6023 & 97.9413 & 94.4154 & 98.0493 & 98.4168 \\
\cline { 2 - 7 } & Kappa(\%) & 89.1887 & 95.8800 & 88.8128 & 96.0960 & 96.8318 \\
\hline \multirow{2}{*}{ Image 3 } & $\begin{array}{c}\text { Overall } \\
\text { accuracy(\%) }\end{array}$ & 91.3483 & 87.4061 & 90.2469 & 88.3248 & 88.2388 \\
\cline { 2 - 7 } & Kappa(\%) & 82.6271 & 75.0928 & 80.4989 & 74.6937 & 74.5165 \\
\hline
\end{tabular}

Table 4. Comparison of different cases of object oriented classifiction

\begin{tabular}{|c|c|c|c|}
\hline \multirow{2}{*}{ Method of classification } & Optimum case of object based & Pixel based \\
\hline \multirow{2}{*}{ Image 1 } & Overall accuracy(\%) & 91.1715 & 77.3715 \\
\cline { 2 - 4 } & Kappa(\%) & 80.0395 & 47.6401 \\
\hline \multirow{2}{*}{ Image 2 } & Overall accuracy(\%) & 98.4168 & 84.3317 \\
\cline { 2 - 4 } & Kappa(\%) & 96.8318 & 68.7228 \\
\hline \multirow{2}{*}{ Image 3 } & Overall accuracy(\%) & 91.3483 & 81.8484 \\
\cline { 2 - 4 } & Kappa(\%) & 82.6271 & 62.6401 \\
\hline
\end{tabular}

Table 5. Comparison the result of object oriented classification with pixel based classification 
The International Archives of the Photogrammetry, Remote Sensing and Spatial Information Sciences, Volume XL-1/W5, 2015 International Conference on Sensors \& Models in Remote Sensing \& Photogrammetry, 23-25 Nov 2015, Kish Island, Iran

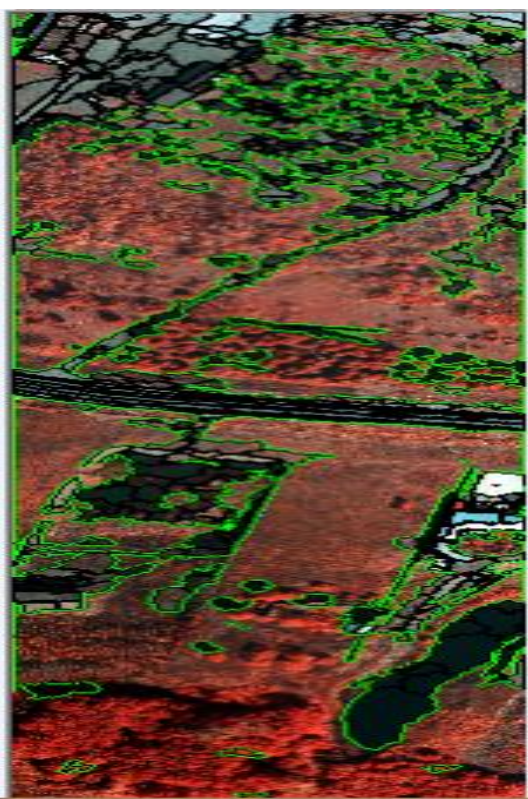

a

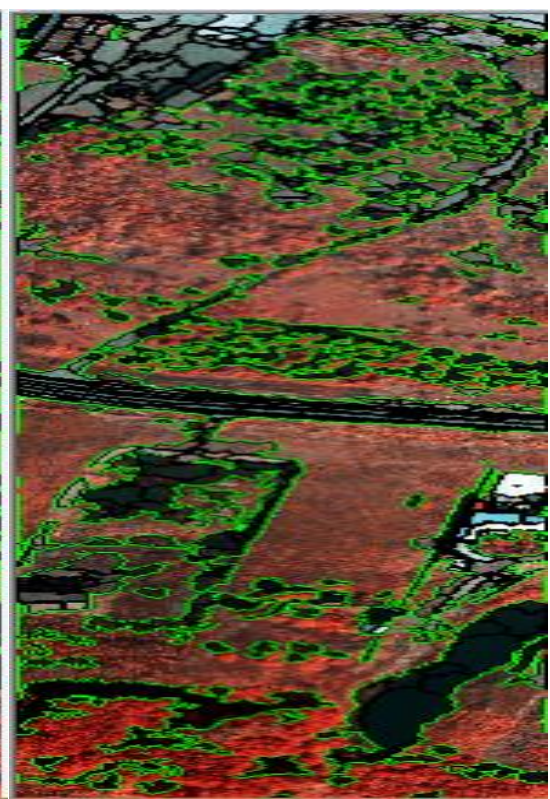

b

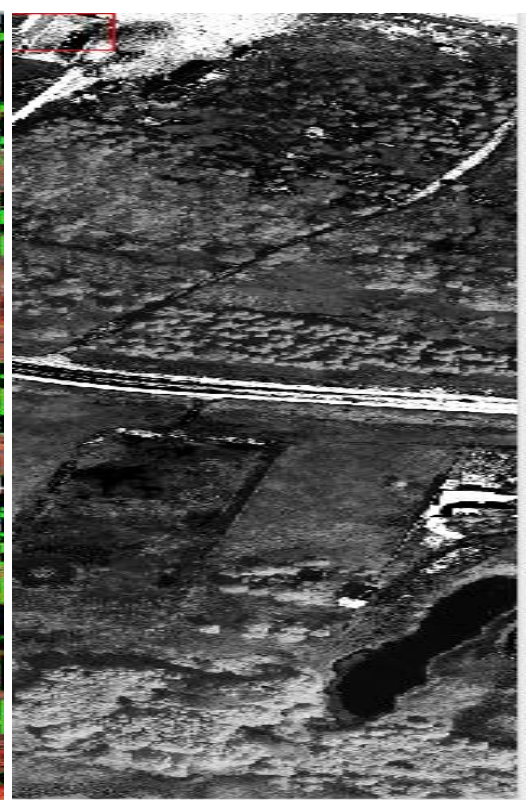

$\mathrm{c}$

Fig 2. Results for parts of image 1(NIR band instead of Red band), a) optimum OBC (green edges are boundaries of vegetation (merged)), b) ground truth image, c) pixel based classification

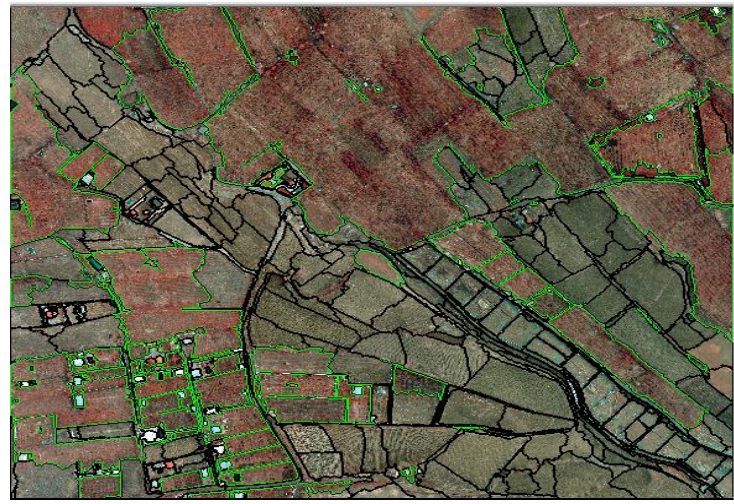

a

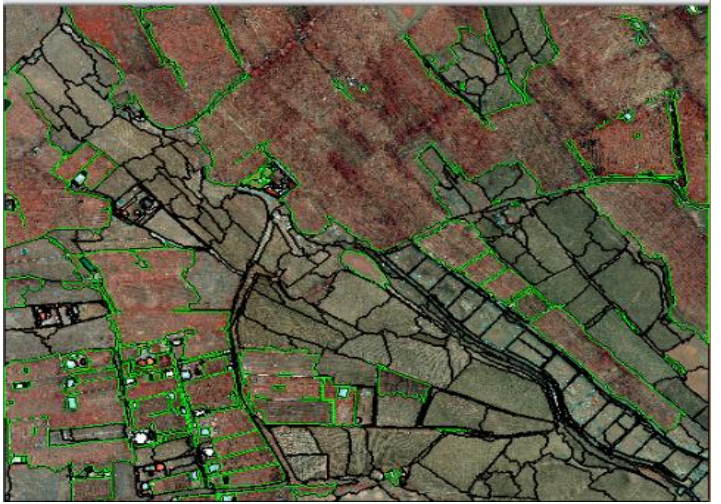

$\mathrm{b}$

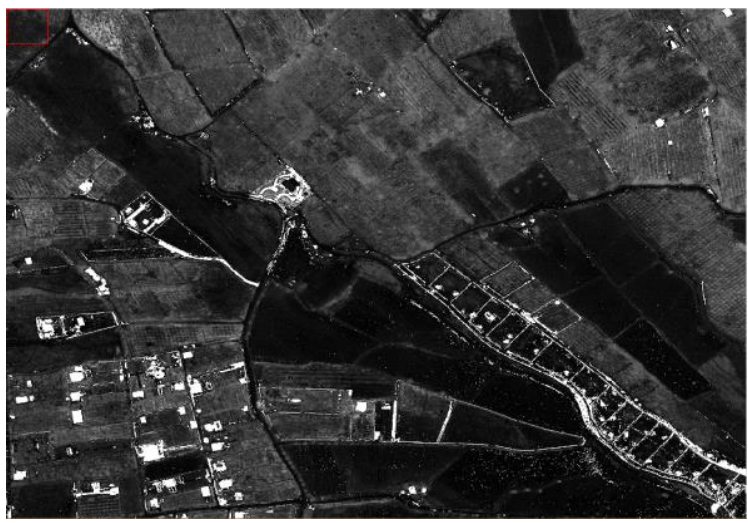

$\mathrm{c}$

Fig 3. Results for image 2 (NIR band instead of Red band), a) optimum OBC (green edges are boundaries of vegetation (merged)), b) ground truth image, c) pixel based classification 


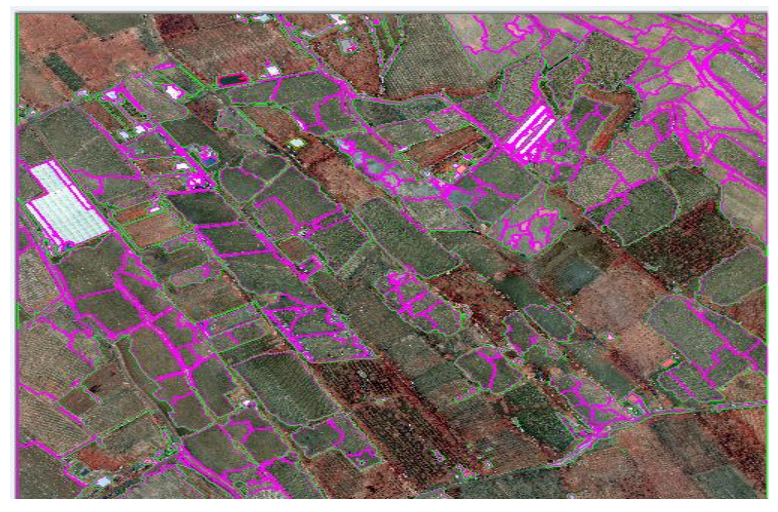

a

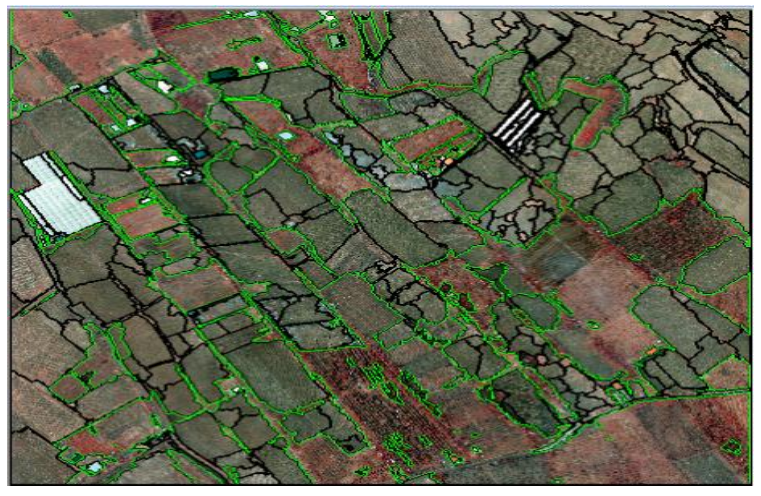

b

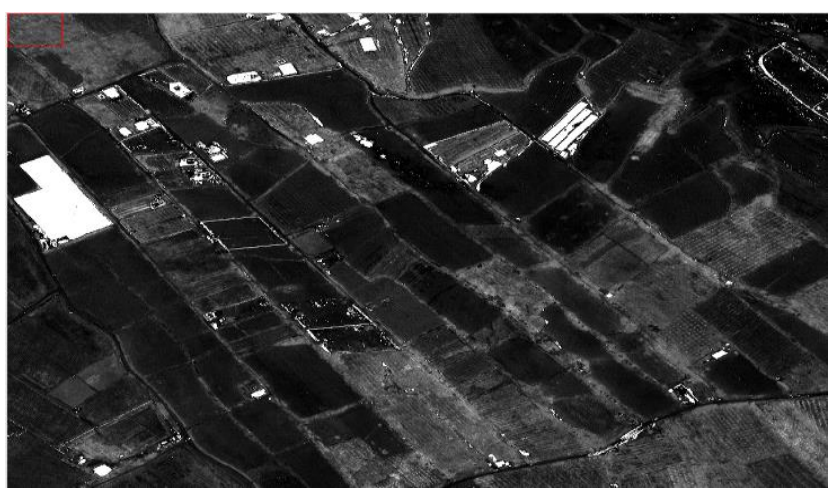

C

Fig 4. Results for image 3 (NIR band instead of Red band), a) optimum OBC (green edges are boundaries of vegetation (merged), pink edges are boundaries of soil), b) ground truth image, c) pixel based classification

Using different vegetation indices in object-based classification along with sampling implies that DVI and RDVI lead to best results in terms of overall accuracy and Kappa. Because Kappa of RDVI is not proper on the image 2 , DVI is selected as the optimum vegetation index with $92.6 \%$ overall accuracy and $83.8 \%$ Kappa. DVI is less affected by background spectra (Roujean and Breon, 1995). Furthermore, although NDVI is a proper index for extracting vegetation, its relation with vegetation amount is non-linear (Fig. 2) and doesn't perform well in shrub and grassland classes (Montandon and Small, 2008). These prove that DVI's performance is better for vegetation extraction compared to NDVI.

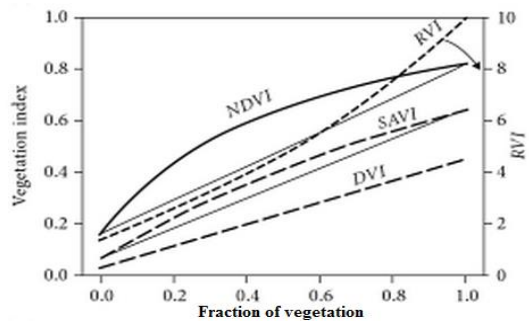

Fig 2. Calculated variation for vegetation indices as a function of fractional vegetation cover (Jones and Vaughan, 2010)
Indices which use only ratios of visible bands had lower accuracy than those with NIR band. For instance, DVI and RDVI which use NIR band had average overall accuracy of $92 \%$ and $91 \%$ respectively on the three test images while NDI and DGR which use only visible bands had overall accuracy of $55 \%$ and $53 \%$ respectively. As a result of this considerable difference, it is suggested to use indices with NIR bands for vegetation extraction.

In all test images, object-based approach gives better results than pixel-based approach and its outputs are visually more interpretable and better understood. Results showed that the object-based classification with average $93.6 \%$ overall accuracy and $86.5 \%$ Kappa was better for vegetation extraction than the pixel-based classification with average $81.2 \%$ overall accuracy and $89.7 \%$ Kappa. The high difference between overall accuracy and Kappa in pixelbased method illustrates its low accuracy and the effects of omission and commission errors which have decreased Kappa considerably .

The order of applying features also affects classification results. It was found that in image 1 , if the defined indices for soil and shadow are first applied and then the merging feature is used for the building class, there will be more classification errors compared to the case where the merging 
feature is first applied to the building class. Therefore, extracted features form an image may lead to good results only if a specific order of actions is taken. When this order changes, features seem to be unsuitable for the purpose.

All tested cases with DVI showed that if samples are used, results will improve. The amount of this difference in all images is approximately $2 \%$ for overall accuracy and $6 \%$ for Kappa which is negligible. In practice, sampling is done only when a high accuracy is required.

Definition of other classes decreased the overall accuracy in image $1 \& 2$ but increased it $4 \%$ in the image 3 . So, to use this case or not depends on the image itself. The image $1 \&$ 2 had denser vegetation and higher reflectance in NIR band in comparison to the image 3 These differences makes the definition of other classes to be effect less in these images because vegetation segments are well segmented due to the higher weight of NIR band and less combination with the covers like soil which degrades the accuracy in most images.

Definition of other features like NDWI increased the accuracy in image $1 \& 2$ ( $2 \%$ and $4 \%$ overall accuracy increase, and Kappa increase of $4 \%$ and $7 \%$ respectively when using samples) while decreased the accuracy in the image 3. So to use this case or not depends also to the image itself. Image 1 has numerous water basins and because NDWI improves results of images with highly water contained vegetation and water decreases reflectance in NIR band, using this index improves the results of this image.

\section{CONCLUSION}

Vegetation is counted as one of the most important component in each ecosystem. Performance of indices on images of different sensors are not same and there is no optimum index for all images. Also different extraction methods leads to different results. To study this matter on high resolution images different vegetation indices were tested on UltraCam images and their overall accuracy and Kappa were calculated and compared to each other. In addition, various vegetation extraction methods including pixel-based and object-oriented were studied in semi-urban and agricultural regions. Next, different cases of objectoriented classification (presence or absence of sample data, using other features such as NDWI, Brightness etc. and definition of other classes like water, soil and others.) and pixel-based classification were evaluated and compared. After all these, it is concluded that among different indices, DVI leads to better results for extracting vegetation in test images. The reason for this is that DVI is less sensitive to background spectra, has linear relation with vegetation amount and better preforms in areas with low vegetation. Moreover, results showed that object-oriented classification with $93.6 \%$ overall accuracy and $86.5 \%$ Kappa could better extract vegetation in test images and got more real results in comparison to pixel-based classification with $81.2 \%$ overall accuracy and $59.7 \%$ Kappa.

\section{REFERENCES}

Baatz, M., Schape, A., 2000. Multiresolution segmentation: an optimization approach for high quality multi-scale image segmentation, In: Strobl, J., et al.(Eds.): Angewandte Geographische Informationsverarbeitung, Vol. XII, Karlsruhhe:Herbert Wichman, pp. 12-23.

Barati, S., Raiegani, B., Saati, M., Sharifi, A., Nasri, M., 2011. Comparison the accuracies of different spectral indices for estimation of vegetation cover fraction sparse vegetated areas. The Egyptian Journal of Remote Sensing and Space Sciences 14, pp. 49-56.

Bargen V.K. Mortensen D. A. Woebbecke D. M., Meyer G. E, 1995. Color indices for weed identi_cation under various soil, residue, and lighting conditions. Transactions of the ASAE 38, pp. 259-269.

Blaschke, T., 2010. Object Based Image Analysis for Remote Sensing. ISPRS Journal of Photogrammetry and Remote Sensing 65, pp. 2-16.

Buschmann, C., Nagel, E., 1993. In vivo spectroscopy and internal optics of leaves as basis for remote sensing of vegetation .Int. J.Remote Sens 14(4),pp.711-722.

Cover, T.M., Hart, P.E., 1967. Nearest neighbor pattern classification. IEE transcations on information theory, vol. IT-13, No. 1.

Gao, B. C. 1996. NDWI - A normalized difference water index for remote sensing of vegetation liquid water from space. Remote Sensing of Environment 58, pp. 257-266.

Gitelson, A. A., Kaufman, Y.J., Merzlyak, M.N., 1996. Use of a green channel in remote sensing of global vegetation from EOS-MODIS. Remote Sensing of Environment 58, pp. 289-298.

Huete, A. R., 1988, A soil adjusted vegetation index SAVI. Remote Sensing of Environment 25, pp. 295-309.

Jones, H.G., Vaughan, R.A., 2010. Remote sensing of vegetation: principles, techniques, and applications. pp. 173.

Li, X., Shao, G., 2014, Object-based land-cover mapping with high resolution aerial photography at a county scale in midwestern USA, Remote Sens 6, pp. 11372-11390.

Liu, S., Du, P. , 2008. Object-Oriented Change Detection from Multi-Temporal Remotely Sensed Images. The International Archieve of the Photogrammetry, Remote Sensing and Spatial Information Sciences XXXVIII, part 4/C7.

Mathieu, R., M. Pouget, B. Cervelle, and R. Escadafal, 1998. Relationships between satellite-based radiometric indices simulated using laboratory reflectance data and typical soil color of an arid environment, Remote Sens. Environ 66, pp. 17- 28 .

Montandon, L.M., Small, E.E., 2008. The impact of soil reflectance on the quantification of the green vegetation 
fraction from NDVI. Remote Sensing of Environment 112, $1835-1845$.

Myint, S.W., Gober, P., Brazel, A., Grossman-Clarke, S., Weng, Q., 2011. Per-pixel vs. object-based classification of urban land cover extraction using high spatial resolution imagery, Remote Sensing of Environment 115, pp. 11451161.

Navulur, K., 2006, Multispectral Image Analysis Using the Object-Oriented Paradigm. Taylor \& Francis Group.

Pu, R., Landry, S., Yu, Q., 2011. Object-Based Landscape Analysis. International Journal of Remote Sensing 32:12, pp. 3285-3308.

Roujean, J.L, Breon, F.M, 1995. Estimating PAR absorbed by vegetation from bidirectional reflectance measurements. Remote Sense. Environ. 51, pp. 375- 384.

Rouse, J. W., Haas, R.H., Schell, J.A., Deering, D.W. 1973. Monitoring vegetation systems in the Great Plains with ERTS. In: Third ERTS Symposium. NASA, pp. 309-317

Tucker, C.J. 1979. Red and photographic infrared linear combinations for monitoring vegetation. Remote Sensing of Environment 8: 127-150.

Vescovo, L., Gianelle, D., 2008. Using the MIR bands in vegetation indices for the estimation of grassland biophysical parameters from satellite remote sensing in the Alps region of Trentino (Italy). Advances in Space Research 41, pp. 1764-1772.

Wei, L., Li, P., Zhong, Y. 2009. An Advanced Change Detection Methode Based on Object-oriented Classification of Multi-band Remote Sensing Image. Geoinformatics, 18th International Conference on.: 1-6.

Wobbecke, D. M., G. E. Meyer, K. Von Bargen, and D. A. Mortensen. 1995. Color indices for weed identification under various soil, residue, and lighting conditions. Trans. ASAE 38(1), pp. 259-269.

Yan, G., Mas J.F., Maathuis, B.H.P., Xiangmin, Z., Van Dijk, P.M., 2006. Comparison of Pixel-Based and ObjectOriented Image Classification Approaches-A Case Study in A Coal Fire Area, Wuda, Inner Mongolia, China. International Journal of Remote Sensing 27, pp. 4039-4055. 